\title{
Assessment of electrical conversion of supraventricular arrhythmias*
}

\author{
R. J. KERNOHAN \\ M.D., F.R.C.P.I. \\ Department of Cardiology, Waveney Hospital, Ballymena, N. Ireland
}

\begin{abstract}
Summary
Direct current shock therapy in 244 cases of atrial fibrillation, fifty cases of paroxysmal supraventricular tachycardia, and eighteen cases of atrial flutter has been assessed. The administration of intravenous diazepam (Valium) allowed direct current shock therapy without general anaesthesia and tracheal intubation.
\end{abstract}

Seventy percent of cases of atrial fibrillation, $96 \%$ of cases of paroxysmal supraventricular tachycardia, and $94 \%$ of cases of atrial flutter reverted to sinus rhythm. The 190 patients first treated were followed up after the attempt at conversion until relapse of the arrhythmia or for a minimum of 2 years. The best results were obtained in arrhythmia of thyrotoxic aetiology. In patients with ischaemic/hypertensive heart disease and rheumatic heart disease the results were disappointing.

The success rate with direct current shock therapy is inversely related to the cardiothoracic index, and with increase in heart size there is also deterioration in the long-term results. Only one of the patients who had a cardiothoracic index of more than $55 \%$ remained in sinus rhythm at the end of 2 years.

The success rate decreases with increasing duration of the preceding arrhythmia, particularly when it had been present for more than 1 year, and the stability of the attained sinus rhythm also decreases with increasing duration of the preceding arrhythmia.

Direct current shock therapy is the method of choice in most cases of atrial flutter. Direct current shock therapy is seldom indicated in paroxysmal supraventricular tachycardia except in cases with underlying serious heart disease. Direct current shock therapy is contra-indicated in digitalis-induced arrhythmias.

\section{Introduction}

In 1962 Lown, Amarasingham \& Neuman introduced the clinical use of direct current shock for the

\footnotetext{
* Presented at Symposium of the Royal College of Physicians of Ireland and the American College of Physicians in Dublin, Eire, on 18 September, 1971.
}

conversion of supraventricular and ventricular arrhythmias to sinus rhythm. An analysis of the immediate and long-term results in supraventricular arrhythmias, and of the complications of the method is presented. This is based on $\mathbf{3 1 2}$ attempts at conversion in 244 cases of atrial fibrillation, fifty cases of paroxysmal supraventricular tachycardia, and eighteen cases of atrial flutter. Cases of supraventricular arrhythmia complicating acute myocardial infarction are not included. The 190 patients first treated were followed up after the first attempt at conversion until relapse of the arrhythmia or for a minimum of 2 years. An assessment is made of criteria which can be applied for the selection of patients with chronic atrial arrhythmias for electrical conversion.

\section{Method}

A total of 443 direct current shocks were given in the course of the 312 attempts to produce electrical reversion in 264 patients. Digitalis preparations were withheld for at least $48 \mathrm{hr}$ before electroconversion. In fifty-two patients, who were on long-term anticoagulant therapy, this treatment was continued. In the remaining 222 patients anticoagulants were not given in connection with the attempt to obtain electrical conversion. Twelve lead standard electrocardiograms and chest radiographs were taken before and after treatment. Diazepam was used for its sedative and hypnotic effect. Its use allowed direct current shock therapy without general anaesthesia and tracheal intubation (Kernohan, 1966; Nutter \& Massumi, 1965). Diazepam was given into an antecubital vein in a dose of $2.5 \mathrm{mg} / 30 \mathrm{sec}$ until sleep was induced. The total dose varied between $10 \mathrm{mg}$ and $65 \mathrm{mg}$ The average dose of diazepam was $30 \mathrm{mg}$ in patients aged $20-50$ years, and $20 \mathrm{mg}$ in patients over the age of 50 years.

After the onset of sleep, direct current shock was delivered by means of shoulder-blade and anterior chest paddles. The cardioverter has a built in synchronizer which is provided with a delay circuit triggered by the $R$ wave of the electrocardiogram. The instrument is set so that the electric shock falls 
20 msec after the peak of the $R$ wave in order to avoid the vulnerable period of the cardiac cycle. This period has a duration of $30 \mathrm{msec}$ and is located at the apex of the $T$ wave. The patients remained in a deep sleep for about $1 \mathrm{hr}$, and on recovery had either no recollection of the shock or just a vague memory of the procedure. In most cases the first shock was 100 Joules. If sinus rhythm was not established and no significant arrhythmia developed after the first shock, further shocks increasing in strength up to 400 Joules were administered. In 213 procedures a single shock was administered; two shocks were administered in sixty-six procedures, and three or more shocks in thirty-three.

\section{Results}

Direct current shock therapy was considered successful if the arrhythmia reverted to sinus rhythm which persisted for at least $24 \mathrm{hr}$. Seventy percent of cases of atrial fibrillation, $96 \%$ of cases of supraventricular tachycardia, and $94 \%$ of cases of atrial flutter reverted to sinus rhythm.

The long-term results in relation to aetiology of the arrhythmia are shown in Table 1 . The best immediate and follow-up results were obtained in patients with atrial arrhythmias of thyrotoxic aetiology. Electrical conversion was not attempted before adequate treatment of hyperthyroidism. In the group of patients with ischaemic and/or hypertensive heart disease the long-term results were disappointing, only $34 \%$ remaining in sinus rhythm at the end of 2 years. The long-term results in patients with rheumatic heart disease, both pre- and postoperative, were even more disappointing, only $19 \%$ remaining in sinus rhythm at the end of 2 years. Cardioversion was not attempted for at least 3 months following cardiac surgery.

The success rate after direct current shock was inversely related to the cardiothoracic index (Table 2). With increase in heart size there was also deterioration in the long-term results. Only one patient, who had a cardiothoracic index of more than $55 \%$, remained in sinus rhythm at the end of the 2-year follow-up.

The reversion rate decreased gradually with increasing duration of the preceding arrhythmia, particularly when it had been present for more than 1 year (Table 3 ). The stability of the attained sinus rhythm also decreases gradually with increasing duration of the preceding arrhythmia. Only one

TABLE 1. Results in relation to aetiology

\begin{tabular}{|c|c|c|c|c|c|c|}
\hline \multirow[t]{2}{*}{ Aetiology } & \multirow[t]{2}{*}{$\begin{array}{l}\text { No. of } \\
\text { patients }\end{array}$} & \multirow[t]{2}{*}{$\begin{array}{l}\% \text { reverted to } \\
\text { sinus rhythm }\end{array}$} & \multicolumn{4}{|c|}{$\begin{array}{l}\% \text { of patients remaining in } \\
\text { sinus rhythm after more than: }\end{array}$} \\
\hline & & & 3 months & 6 months & 1 year & 2 years \\
\hline Ischaemic/hypertensive & 95 & 62 & 48 & 47 & 40 & 34 \\
\hline $\begin{array}{l}\text { Rheumatic heart disease } \\
\text { Mitral valve disease - postvalvotomy }\end{array}$ & 30 & 47 & 30 & 30 & 20 & 10 \\
\hline or valve replacement & 13 & 77 & 46 & 46 & 46 & 38 \\
\hline Thyrotoxic & 21 & 95 & 86 & 81 & 76 & 71 \\
\hline
\end{tabular}

TABLE 2. Results in relation to heart size

\begin{tabular}{|c|c|c|c|c|c|c|}
\hline \multirow[t]{2}{*}{$\begin{array}{l}\text { Heart size } \\
\text { CT ratio }\end{array}$} & \multirow[t]{2}{*}{$\begin{array}{c}\text { No. of } \\
\text { patients }\end{array}$} & \multirow[t]{2}{*}{$\begin{array}{l}\% \text { reverted to } \\
\text { sinus rhythm }\end{array}$} & \multicolumn{4}{|c|}{$\begin{array}{l}\% \text { of patients remaining in } \\
\text { sinus rhythm after more than: }\end{array}$} \\
\hline & & & 3 months & 6 months & 1 year & 2 years \\
\hline $\begin{array}{r}<50 \% \\
50-55 \% \\
>55 \%\end{array}$ & $\begin{array}{r}123 \\
52 \\
15\end{array}$ & $\begin{array}{l}79 \\
56 \\
40\end{array}$ & $\begin{array}{l}67 \\
40 \\
20\end{array}$ & $\begin{array}{l}63 \\
40 \\
13\end{array}$ & $\begin{array}{l}60 \\
25 \\
13\end{array}$ & $\begin{array}{r}54 \\
13 \\
6\end{array}$ \\
\hline
\end{tabular}

TABLE 3. Results in relation to duration of preceding arrhythmia

\begin{tabular}{|c|c|c|c|c|c|c|}
\hline \multirow[t]{2}{*}{$\begin{array}{l}\text { Duration of atrial } \\
\text { arrhythmia preceding } \\
\text { direct current shock }\end{array}$} & \multirow[t]{2}{*}{$\begin{array}{c}\text { No. of } \\
\text { patients }\end{array}$} & \multirow[t]{2}{*}{$\begin{array}{l}\% \text { reverted to } \\
\text { sinus rhythm }\end{array}$} & \multicolumn{4}{|c|}{$\begin{array}{l}\% \text { of patients remaining in } \\
\text { sinus rhythm after more than: }\end{array}$} \\
\hline & & & 3 months & 6 months & 1 year & 2 years \\
\hline $\begin{array}{l}1 \text { month } \\
1-6 \text { months } \\
6-12 \text { months } \\
1-3 \text { years } \\
>3 \text { years }\end{array}$ & $\begin{array}{l}37 \\
58 \\
11 \\
54 \\
30\end{array}$ & $\begin{array}{l}92 \\
90 \\
91 \\
50 \\
30\end{array}$ & $\begin{array}{l}86 \\
76 \\
64 \\
28 \\
20\end{array}$ & $\begin{array}{l}81 \\
71 \\
64 \\
28 \\
20\end{array}$ & $\begin{array}{r}76 \\
64 \\
55 \\
24 \\
7\end{array}$ & $\begin{array}{r}62 \\
60 \\
36 \\
20 \\
3\end{array}$ \\
\hline Total & 190 & 70 & 55 & 52 & 45 & 39 \\
\hline
\end{tabular}


TABLE 4. Results in patients reverted to sinus rhythm in relation to the energy level

\begin{tabular}{|c|c|c|c|c|c|}
\hline \multirow[t]{2}{*}{$\begin{array}{l}\text { Energy level } \\
\text { (Joules) }\end{array}$} & \multirow[t]{2}{*}{$\begin{array}{l}\text { No. of patients } \\
\text { reverted to } \\
\text { sinus rhythm }\end{array}$} & \multicolumn{4}{|c|}{$\begin{array}{l}\% \text { of patients remaining in } \\
\text { sinus rhythm after more than: }\end{array}$} \\
\hline & & 3 months & 6 months & 1 year & 2 years \\
\hline $\begin{array}{r}50-100 \\
(1 \text { shock })\end{array}$ & 11 & 91 & 73 & 64 & 55 \\
\hline $\begin{array}{c}100-200 \\
(1 \text { shock })\end{array}$ & 95 & 80 & 76 & 65 & 52 \\
\hline $\begin{array}{c}300-550 \\
(2 \text { shocks })\end{array}$ & 22 & 55 & 41 & 36 & 32 \\
\hline $\begin{array}{c}650-1000 \\
(3 \text { or more shocks) }\end{array}$ & 4 & 50 & 0 & 0 & 0 \\
\hline
\end{tabular}

patient who had atrial flutter or fibrillation for more than 3 years before treatment remained in sinus rhythm at the end of 2 years.

Table 4 shows the results in relation to the energy level required for the patient to revert to sinus rhythm. Early relapses were more frequently observed in patients who needed a high energy level for reversion. There is a marked difference in the long-term results between those patients who reverted with 200 Joules or less and those who needed 300 or more Joules. Patients with atrial flutter reverted to sinus rhythm with lower energy levels than those with atrial fibrillation, all cases of atrial flutter except two, achieving sinus rhythm with 100 Joules or less.

Eighteen patients who had reverted from atrial fibrillation to sinus rhythm on the first attempt and in whom atrial fibrillation recurred, were treated for a second time. Four patients were treated a third time, and one patient a fourth time. Of the eight patients treated successfully, sinus rhythm was maintained for a shorter period after the subsequent attempt than after the first attempt. Only three of these patients remained in sinus rhythm for more than 6 months after the subsequent attempt.

Eight patients with paroxysmal supraventricular tachycardia were treated with direct current shock on multiple occasions. One patient, who was subject to paroxysmal supraventricular tachycardia with a ventricular response of $200 / \mathrm{min}$ and aberrant ventricular conduction, has been treated successfully on ten occasions.

\section{Complications}

Three categories of complication may occur in connection with direct current shock therapy:

(1) Complications related to direct current shock itself.

(2) Complications related to the reversion of the atrial arrhythmia.

(3) Complications related to the anaesthesia.

(1) Transient, multiple, ventricular ectopics were frequent immediately after direct current shock, both in patients who reverted to sinus rhythm and in patients who did not. Transient nodal rhythm was common. One patient developed ventricular tachycardia which reverted spontaneously to the original atrial fibrillation. Two patients developed transient bradycardia due to atrioventricular heart block.

Improperly synchronized direct current shock falling within the vulnerable period of the cardiac cycle may produce ventricular fibrillation (Resnekov \& McDonald, 1968). Direct current shock may potentiate the action of digitalis especially if there is associated hypokalaemia due to diuretic therapy (Upton \& Honey, 1971). Most cases of ventricular fibrillation which have been reported following direct current shock, have been associated with digitalis administration (Gilbert \& Cuddy, 1965). A likely explanation is that electrical discharge affects myocardial cell membranes resulting in a leakage of intracellular potassium (Kleiger \& Lown, 1966). In this series, digitalis was omitted for $48 \mathrm{hr}$ before the procedure and no case of ventricular fibrillation occurred. Ventricular ectopic beats, especially if they increase in number after the first direct current shock, are a warning of impending ventricular fibrillation if another shock is given.

(2) The hazard of embolization is inherent in restoration of sinus rhythm in patients with either atrial fibrillation or flutter regardless of the method of treatment. Of the 264 patients in this series, five experienced an embolic episode in connection with the treatment. Two episodes involved peripheral limb arteries, two the pulmonary arteries, and one a cerebral artery. Three of the episodes occurred in patients with rheumatic valve disease. Two of the five patients were on anticoagulant therapy. Because of this low incidence of embolization and the lack of convincing evidence of real protection from it by means of short-term anticoagulant therapy (Selzer et al., 1966), anticoagulant therapy was not used routinely in this series in preparation for direct current shock except in patients who were on longterm anticoagulant therapy or who had had an embolic episode in the immediate past. 
(3) Intravenous diazepam produced satisfactory sedation, analgesia and amnesia in all patients with the exception of one 25-year-old man in whom a dose of $65 \mathrm{mg}$ was not effective. Complete recovery from the effect of the drug occurred within $1 \mathrm{hr}$ in most cases. Occasionally a patient remained somnolent for several hours. Venous thrombosis at the injection site was not observed. In forty-one cases there was a fall in the mean arterial blood pressure varying between $10 \mathrm{mmHg}$ and $40 \mathrm{mmHg}$. No clinical evidence of circulatory impairment was detected in any case which exhibited a fall in blood pressure. Intravenous diazepam offers a unique advantage in that anaesthesia is not required for the procedure.

\section{Discussion}

Now that the initial enthusiasm for converting every patient with chronic atrial arrhythmia has subsided, more meaningful criteria can be applied for the selection of patients for elective cardioversion by direct current shock. In essence, conversion should be attempted when there is a reasonable expectation of maintaining sinus rhythm. The indications for cardioversion must be carefully considered in each individual patient.

Atrial fibrillation is the commonest of the atrial arrhythmias, and presents a wide range of therapeutic problems. In patients with moderate or severe cardiac enlargement, the long-term results following conversion to sinus rhythm by direct current shock are disappointing. The long-term results are also disappointing in patients in whom the arrhythmia has been present for 1 year or longer. The best results in cases of atrial fibrillation in this series were obtained in treated thyrotoxicosis. There is little advantage in direct current shock therapy to patients in whom the sum total of factors points against the probability of lasting restoration of sinus rhythm. Of these factors the most important are moderate or marked cardiomegaly and duration of the arrhythmia of more than 1 year. A second attempt at cardioversion by direct current shock is probably not justified if atrial fibrillation recurs within 6 months of successful cardioversion. It is inappropriate to repeat multiple praecordial shocks merely to maintain a sinus rhythm.

The benign nature of paroxysmal supraventricular tachycardia calls for the use of direct current shock only under exceptional circumstances. Indications for direct current shock therapy include unusually long duration of the arrhythmia with failure to respond to drug therapy. Paroxysmal supraventricular tachycardia may require electrical termination if there is underlying serious heart disease in which a rapid ventricular rate is poorly tolerated. Direct current shock therapy is contra-indicated for atrial tachycardia appearing as a manifestation of digitalis toxicity. Such cases of digitalis-induced arrhythmia should be treated by omission of digitalis and the administration of potassium and an anti-arrhythmic drug (Turner, 1966).

Atrial flutter is most commonly encountered in persons with ischaemic heart disease over the age of 40 years. In many cases of atrial flutter there is no significant cardiac enlargement. Direct current shock therapy is the method of choice in most patients with atrial flutter. As a rule, conversion to sinus rhythm is achieved with a lower energy level than in atrial fibrillation. An energy level of 20-50 Joules may be successful. In this series $90 \%$ of cases of atrial flutter reverted to sinus rhythm with a shock of 100 Joules or less. Electric shock of $\mathbf{4 0}$ Joules or less is painless and can be tolerated without an anaesthetic agent.

Long-term therapy with quinidine has been recommended following conversion to maintain sinus rhythm. There is no statistical evidence that quinidine is effective in maintaining sinus rhythm after successful conversion by direct current shock therapy (Resnekov \& McDonald, 1968). Prophylactic quinidine is not without inherent risks of precipitating lifethreatening ventricular arrhythmias (Selzer \& Wray 1964). For these reasons quinidine was not used in this series following conversion of supraventricularo arrhythmia to sinus rhythm.

\section{References}

Gilbert, R. \& Cuddy, R.P. (1965) Digitalis intoxication following conversion to sinus rhythm. Circulation, 32, 58. KERNOHAN, R.J. (1966) Letter to Editor. Lancet, i, 718.

KLEIGER, R. \& LowN, B. (1966) Cardioversion and digitalis: II. Clinical studies. Circulation, 33, 878.

Lown, B., Amarasingham, R. \& Neuman, J. (1962) New method for terminating cardiac arrhythmias: use of synchronized capacitor discharge. Journal American Medical Association, 182, 548.

NutTER, D. O. \& MASSUMI, R.A. (1965) Diazepam in cardioversion. New England Journal of Medicine, 273, 650.

Resnekov, L. \& McDonald, L. (1968) Appraisal of electroconversion in treatment of cardiac dysrhythmias. British Heart Journal, 30, 786.

Selzer, A. \& Wray, H.W. (1964) Quinidine syncope. Paroxysmal ventricular fibrillation occurring during treatment of chronic atrial arrhythmias. Circulation, 30, 17.

Selzer, A., Kelly, J.J., Johnston, R.B. \& KeRTir, W.J. (1966) Immediate and long-term results of electrical conversion of arrhythmias. Progress in Cardiovascular Diseases. 9, 90.

TURner, J.R.B. (1966) Propranolol in the treatment of digitalis-induced and digitalis-resistant tachycardias. American Journal of Cardiology, 18, 450.

UPTON, A.R.M. \& HoNEY, M. (1971) Electroconversion of atrial fibrillation after mitral valvotomy. British Heart Journal, 33, 732. 